\title{
A comparison between a combination of ipratropium bromide plus fenoterol in single metered dose inhaler (Duovent) and salbutamol in asthma
}

\author{
K. C. FLINT \\ M.R.C.P.
}

\author{
B. HOCKLEY \\ B.Sc.
}

\author{
N. McI. JOHNSON \\ M.D., M.R.C.P.
}

The Medical Unit, The Middlesex Hospital, London WI

\begin{abstract}
Summary
The efficacy of a single metered dose inhaler containing a combination of fenoterol $(100 \mu \mathrm{g} /$ puff) and ipratropium bromide ( $40 \mu \mathrm{g} /$ puff) has been assessed in 12 asthmatics. We conclude that the bronchodilator effect of 2 puffs of the combination inhaler was significantly greater than that achieved by 2 puffs of salbutamol (100 $\mu \mathrm{g} /$ puff).
\end{abstract}

KEY WORDS: fenoterol, ipratropium bromide, salbutamol, asthma.

\section{Introduction}

Both salbutamol and fenoterol are selective $\beta_{2}$ adrenergic agonists which produce effective bronchodilatation in asthma. Ipratropium bromide is a synthetic anti-cholinergic bronchodilator which has been assessed in both asthma and bronchitis (Poppius and Salorinne, 1973; Petrie and Palmer, 1975). In severe chronic bronchitis and emphysema, it has been shown to be at least as effective as salbutamol, the most commonly used $\beta_{2}$ adrenergic agonist with bronchodilator properties (Douglas et al., 1979).

The combination of fenoterol and ipratropium bromide has been shown to produce a greater bronchodilator response than that achieved by either agent alone both in asthma (Martin, Berend and Harrison, 1979) and chronic bronchitis (Addis, Barclay and Chang, 1979; Anderson, Jariwalla and Turnbull, 1980). This combination has recently become available in a single metered dose inhaler.

In a double-blind, crossover study we have compared the onset of action, peak effect and side effects of this combination with salbutamol similarly administered.

\section{Methods}

Twelve chronic stable asthmatics (5 male, mean age 52 years, range 24-75 years, mean duration of disease 15.5 years) were assessed at the same time on 2 consecutive days having taken no bronchodilator for at least $12 \mathrm{hr}$. Five patients were on inhaled $\beta_{\nexists}^{N}$ adrenergic agonists only, 5 were on inhaled and 2 were on oral corticosteroids. All were non-smokers. $\rightarrow$

After $5 \mathrm{~min}$ rest, baseline measurement of pulse $z$ blood pressure, forced expiratory volume in 1 \& $\left(F_{1}\right)$ and forced vital capacity (FVC) were re $\frac{\Phi}{3}$ corded. FEV 1 and FVC were taken as the best of $\mathrm{P}_{0}$ recordings. After inhalation of 2 puffs of salbutangor $(200 \mu \mathrm{g})$ or 2 puffs of Duovent (the combination 20 $200 \mu \mathrm{g}$ of fenoterol plus $80 \mu \mathrm{g}$ of ipratropium bromg [2 puffs]) from identical inhalers, pulse rate, FEM and FVC were recorded every $10 \mathrm{~min}$ for $0.5 \mathrm{hr}$, then every $15 \mathrm{~min}$ for a further $90 \mathrm{~min}$. Blood pressure was recorded at 1 and $2 \mathrm{hr}$.

\section{Results}

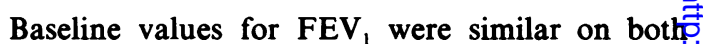
treatment days (combination mean 1.4 litres \pm 0.235 s.e.m. and salbutamol 1.34 litres \pm 0.22 ). The bron 3 . chodilator effect of the combination was significantly. greater than that of salbutamol from 20 to $120 \mathrm{~min}$. inclusive $(P<0.05$ at 20,30 and $45 \mathrm{~min}, P<0.01$ ap $60,75,90,105$ and $120 \mathrm{~min}$ ). Peak values obtained were 1.88 litres \pm 0.26 at $45 \mathrm{~min}$ for salbutamol, and 1.98 litres \pm 0.35 at $60 \mathrm{~min}$ for the combination.

Significant differences were observed for posttreat ment FVC in favour of the combination from 30 to $105 \mathrm{~min}$ inclusive $\left(P<0.05\right.$ at 60 and $105 \mathrm{~min}^{\circ}$ $P<0.01$ at $30,45,75$ and $90 \mathrm{~min})$. Peak values weres obtained with salbutamol at $1 \mathrm{hr}(3.25$ litres $\pm 0.38 \%$ and with the combination at $45 \mathrm{~min}(3.3 \%$ litres $\pm 0 \cdot 38$ ). When percentage increases rather tham absolute values were considered significant differ ences for percentage increase in $\mathrm{FEV}_{1}$ from 75 to $12 \sigma^{\circ}$ 
min inclusive $(P<0.05$ for $105 \mathrm{~min}$, and $P<0.01$ at 75, 90 and $120 \mathrm{~min}$ ). However, there were no significant differences observed between the treatments for percentage increase in FVC. There was no significant difference between salbutamol and the combination with respect to pulse rate and blood pressure before and after treatment and no difference related to the order of treatments.

Tremor was a common side effect (5 out of 12) but was equally common with salbutamol and the combination. Two patients complained of the taste of the combination. One patient felt nauseated with the combination.

\section{Diecussion}

The different sites of action of $\beta_{2}$ adrenergic agonists and anti-cholinergic agents has led to their use in combination in patients with chronic airways obstruction. The combination of fenoterol with ipratropium bromide has been shown to produce additional bronchodilatation (Martin, Berend and Harrison, 1979) and in a single metered dose inhaler, to provide optimal bronchodilatation with few side effects (Ulmer, 1979). This combination inhaler is now widely available in the U.K. and may increase compliance in those patients shown to respond to both agents. There is, as yet however, no published information on the efficacy of this combination in asthma.

We conclude that, at conventional doses ( 2 puffs of the metered dose inhaler, Duovent [the combination of fenoterol (100 $\mu \mathrm{g} / \mathrm{puff})$ and ipratropium bromide (40 $\mu \mathrm{g} /$ puff)] produced significantly greater bronchodilator effect than salbutamol (100 $\mu \mathrm{g} / \mathrm{puff})$.

We have not examined dose response relationships and it is possible that this advantage may be lost at other doses.

\section{References}

ADDis, G.J., Barclay, J. \& Chang, E.M. (1979) Assessment of combination of doses of fenoterol and ipratropium suitable for single metered dose aerosol. European Journal of Clinical Pharmacology, 16, 97.

Anderson, G., Jariwalla, A.G. \& Turnbull, P. (1980) The effects of fenoterol, ipratropium bromide and their combination in asthma and chronic bronchitis. British. Journal of Diseases of the Chest, 74, 416

Douglas, N.J., Davidson, I., Sudlow, M.F. \& Flenley, D.C. (1979) Bronchodilatation and the site of airways resistance in severe chronic bronchitis. Thorax, 34, 51 .

MarTin, G.E., Berend, N. \& Harrison, A.C. (1979) Combined cholinergic antagonist and $\beta_{2}$ adrenoreceptor agonist bronchilator therapy by inhalation. Australian and New Zealand Journal of Medicine, 9, 511.

PeTrie, G.R. \& Palmer, K.N.V. (1975) Comparison of aerosol ipratropium bromide and salbutamol in chronic bronchitis and asthma. British Medical Journal, 1, 430.

PoppiUs, H. \& SAlORINNE, Y. (1973) Comparative trial of a new bronchodilator, Sch 1000 and salbutamol in chronic bronchitis. British Medical Journal, 4, 134.

ULMER, W.T. (1979) The treatment of obstructive airway disease with the metered-dose aerosol containing fenoterol and ipratropium bromide (IK6) Medizinische Klinik, 74, 1548. 